\title{
Cost-Effectiveness of the Biozorb Device for Radiation Planning in Oncoplastic Surgery
}

\author{
Ramy Rashad ${ }^{1,2}$, Kathryn Huber ${ }^{1,2}$, \& Abhishek Chatterjee ${ }^{1,2}$ \\ ${ }^{1}$ Tufts Medical Center, Boston, MA, USA \\ ${ }^{2}$ Tufts University School of Medicine, Boston, MA, USA \\ Corresponding Author: Abhishek Chatterjee, Dept. of Plastic and Reconstructive Surgery, Tufts Medical Center \\ 800 Washington Street Boston, MA 02111, USA. Tel: 617-636-5600. E-mail: \\ Achatterjee1@tuftsmedicalcenter.org
}

Received: October 10, 2018

Accepted: November 2, $2018 \quad$ Online Published: November 6, 2018

doi: $10.5539 /$ cco.v7n2p23

URL: https://doi.org/10.5539/cco.v7n2p23

\begin{abstract}
Purpose:

With the extent of breast tissue manipulation using oncoplastic surgical techniques, there lies a challenge in marking the tumor bed for adjuvant radiation therapy planning. Two competing techniques in doing so exist and involve the traditional placement of surgical clips in the surgical tumor bed or the newer technique of placing a Biozorb marker in the tumor bed. Our goal was to perform a cost-utility assessment to see which tumor bed marking approach is more cost-effective. Based on device list prices and clinical outcomes from a comprehensive literature review, we assessed if an approach either dominated or had an incremental cost-utility ratio of less than $\$ 50,000 / \mathrm{QALY}$ since either would signify cost-effectiveness.
\end{abstract}

Results:

From a cost comparison, the Biozorb marker (\$1250) was far costlier than the clip applier device (\$50). Our PRISMA search (Figure 1) reviewed 133 articles for clip placement and 42 articles for Biozorb placement in oncoplastic surgery with 2 clip placement articles and 3 Biozorb articles meeting criteria. The available data for either marking technique suggests reasonable tumor bed identification for adjuvant radiation treatment without clear clinical advantages supporting one technique over the other. Overall clinical equivalence in the setting of a clear cost advantage suggests dominant cost-effectiveness in favor of clips.

Conclusion:

Using surgical clips to identify the tumor bed in oncoplastic surgery is dominant and more cost-effective over the Biozorb technique as clips are relatively inexpensive while both techniques reasonably identify the tumor bed.

Keywords: Biozorb, cost-effectiveness, oncoplastics, radiation planning, surgical clips

\section{Introduction}

Oncoplastic surgery has gained traction over the last few years as it allows patients to retain a natural appearance following large oncological procedures. The field has established several techniques as its hallmark procedures, which include a variety of mastopexy approaches and reduction mammoplasty techniques (Chatterjee et al., 2017; Masetti et al., 2006; Piper, et al., 2015; Berry et al., 2010). Although cosmetic outcome is a focus of these procedures, the primary indication for the surgery is removal of a tumor. Thus, understanding the impact of these surgeries on oncological treatment is important. In particular, their effect on surgical cavity location is important as it directly informs and directs post-op boost radiation. The large parenchymal shifts resulting from various oncoplastic surgeries make it challenging to assess the tumor bed location without assistance. A couple of studies to date have quantified the large tissue shifts post-oncoplastic surgery to validate the need for a definitive way to define the tumor bed following these surgeries (Kirova et al., 2011; Alco et al., 2016; Eaton et al., 2014).

Historically, imaging modalities, particularly CT scans, have been used to plan for boost radiation therapy following surgery. However, several studies have shown their inconsistency in providing accurate tumor bed coordinates for a variety of reasons, including user variability and variances in patient tissue density and size, and difficulties of visualization due to seroma formation (Bates et al., 2007; Metcalfe et al., 2013; Messer, et al., 
1997; Den et al., 2014; Boersma et al., 2012; Landis, 2007). Over the years, a variety of other tumor marker methods were tried and tested, including embolization coils and a variety of surgical clips (Braeuning et al., 2000). To date, surgical clips have become recognized as the gold standard for tumor bed identification. Many studies have shown their effectiveness in accurately localizing the target volume for radiation purposes, as they have shown to have minimal movement and are easily identifiable on various image modalities (Landis, 2007; Petersen, 2007; Hartough et al., 2011; Oh, 2006; Denham et al., 1991; Bedwinek, 1993; Youn et al., 2015; Weed et al., 2004; Harrington et al., 1996; Penninkhof et al., 2009). Despite the abundance of literature proving their effectiveness, there still remains little literature to date on their use and effectiveness in oncoplastic procedures.

Focal Therapeutics, a medical device company based in Aliso Viejo, CA introduced a novel tumor marker, Biozorb, to the market. It is a 3D implantable device consisting of a framework of six titanium marker clips designed to facilitate identification of the surgical cavity post-op. A study performed by Ward et al. exhibited Biozorb's presence on a variety of imaging modalities, including mammography, ultrasound, MRI, chest radiography, and CT in an effort to increase awareness over its form and appearance (Ward et al., 2018) A more recent study by Wiens at al. demonstrated the device's ability to reduce clinical target volume and planning target volume of boost radiation post-op with statistically significant results (Wiens et al., 2018). However, the authors noted no difference in the ability of the device to reduce radiation to secondary organs, an in fact noted an increase in ipsilateral lung radiation. To date, there have been limited studies evaluating the effectiveness of this device in properly marking the tumor cavity, as it is a fairly new device.

The primary purpose of this study was to evaluate these two competing techniques, the traditional placement of surgical clips in the surgical tumor bed and the placement of the Biozorb marker in the tumor bed in the context of oncoplastic surgery. A comprehensive literature review was undertaken to compare the reported clinical effectiveness of both techniques. A cost comparison analysis was then performed to inform readers of the cost effectiveness of using one marking technique over the other to better inform surgeon decisions.

\section{Methods}

\subsection{Assessing Clinical Outcomes}

In order to assess the clinical outcomes of the two marking techniques, we began by performing a systematic literature review following Preferred Reporting Items for Systematic Reviews and Meta-Analyses (PRISMA) guidelines, shown in Figure 1. Eligible studies included studies evaluating the use of surgical clips and the Biozorb device in the context of oncoplastic surgery. Exclusion criteria included studies with no discussion of these interventions in the context of oncoplastic surgery.

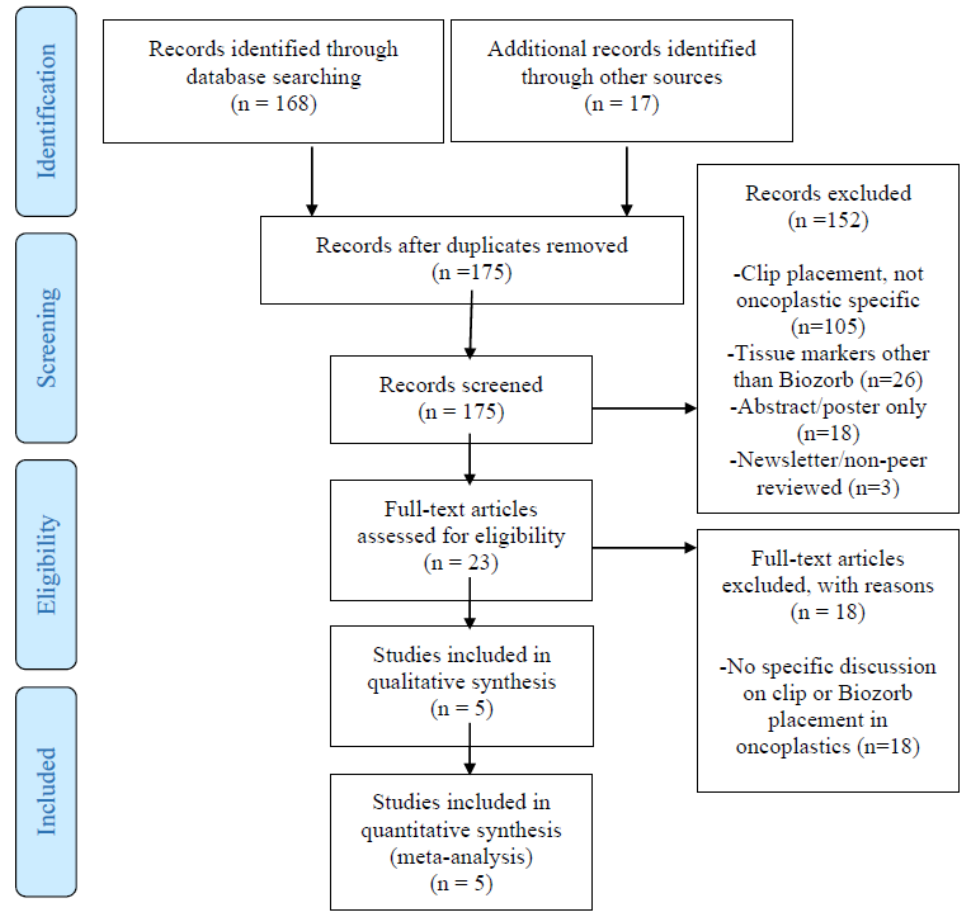

Figure 1. PRISMA 2009 Flowchart for Literature Search on Surgical Clip \& Biozorb Placement in Oncoplastic Surgery 
We searched PubMed and Embase (Ovid) from the inception of each database through February 2018, with the last literature search performed on August 1st, 2018. The search was conducted using the following keywords: "oncoplastic" and "tumor bed identification." To ensure identification of all relevant articles, other additional controlled vocabulary terms (I.e. MeSH terms in PubMed and Emtree terms in Embase) and keywords were used. Search results were then manually reviewed to assess articles specifically discussing Biozorb or surgical clips as the identification methods in oncoplastic surgery.

Two authors (RR, KH) reviewed search results and performed a title and abstract review to evaluate studies for inclusion and exclusion, with disagreements resolved by a third author (AC). Studies meeting inclusion criteria were oncoplastic studies of intraoperative clip or Biozorb placement in defining tumor bed in North America or Europe. Exclusion criteria were as follows: studies evaluating marking modalities other than surgical clips or Biozorb, and non-oncoplastic papers. We also excluded papers not published in American or European journals. We then reviewed the references therein to identify other relevant articles not identified by the original bibliographic search to ensure capture of all relevant articles.

A total of 175 articles were reviewed, 168 from the database search and 17 manually from additional sources.

\subsection{Assessing Cost}

A relatively simple cost comparison was performed involving the direct costs of both medical devices. Given that the oncoplastic operation would involve a similar type of local tissue rearrangement and breast remodeling regardless of the choice of device, it was reasonable to assume that other indirect and direct costs were the same. Therefore, the cost of a clip applier device was found to be $\$ 50$, and the list price of the Biozorb device was found to be $\$ 1,250$, with no other cost differences noted between operations.

\subsection{Assessing Clinical Outcomes}

Our clinical outcomes analysis was based off evidence in present literature depicting how well Biozorb or surgical clips performed in marking a tumor bed. In review of the literature, we hoped to attempt to analyze other clinical outcome parameters such as aesthetics, but could only do this if there was reasonable comparison data on aesthetics comparing Biozorb with surgical clips with reasonable scientific method. Anecdotal statements in presentations or simple case reports were not included.

\subsection{Assessing Dominant Strategy versus Using Incremental Cost-Utility Ratio (ICUR)}

Assuming there is reasonable clinical outcomes data comparing both competing techniques, the next step in cost-utility analysis would be to assess a dominant strategy, if it exists, or to create a decision analytic model evaluating the 2 marking strategies: surgical clips vs. Biozorb if no dominance exists. Central to assessing which device is cost-effective is the use of the incremental cost-utility ratio (ICUR) depicted below:

ICUR $=(($ Expected cost of standard intervention $)-($ Expected cost of competing intervention $)) /(($ Expected

QALY of standard intervention) - (Expected QALY of competing intervention))

ICUR $=(($ Expected cost of surgical clips $)-($ Expected cost of Biozorb $)) /(($ Expected QALY of surgical clips $)-$

\section{(Expected QALY of Biozorb))}

An intervention is deemed "dominant" (and hence cost-effective) if:

1. It has better or equivalent clinical outcome to its competing intervention and is less costly. Dominance with regards to the ICUR is depicted as a negative value or a value approaching infinity (Dukhovny, 2011)

An intervention was deemed "cost effective" if the ICUR is greater than 0 and less than the "willingness to pay" (WTP), for an added year of health. While some studies argue for much higher valuation for added years of life, the majority of studies to date have deemed the WTP to $\$ 50,000$ based on prior studies (Grosse, 2008)(Neumann, Cohen, Weinstein, 2014)(Ubel, Hirth, Chernew, Fendrick, 2003)(Chatterjee et al., 2013)(Chatterjee, 2016)(Asban et al., 2018). If one marking technique is more clinically effective and costs less, then this strategy, by definition dominates as the superior strategy, making it unnecessary to calculate the ICUR (Drummond, 2005).

\section{Results}

\subsection{Literature Review and Clinical Outcomes Results}

The comprehensive systematic literature review yielded a total of 5 article which satisfied all inclusion and exclusion criteria, 3 discussing Biozorb and 2 discussing traditional surgical clips in oncoplastic surgery (Table 1). The five articles pooled a total of 359 patients undergoing oncoplastic surgery with either surgical clips or the Biozorb device as the marking method for post-op boost radiation planning. 
Table 1. Final Included Studies

\begin{tabular}{|c|c|c|c|c|}
\hline Authors & $\begin{array}{l}\text { Number of } \\
\text { Oncoplastic Patients }\end{array}$ & $\begin{array}{l}\text { Marker Type } \\
\text { Studied }\end{array}$ & $\begin{array}{l}\text { Aesthetic } \\
\text { Advantage Studied }\end{array}$ & $\begin{array}{l}\text { Author Final } \\
\text { Recommendations }\end{array}$ \\
\hline $\begin{array}{l}\text { Pezner et al. } \\
2013^{*}\end{array}$ & 25 & Surgical clips & No & $\begin{array}{l}\text { Use 6-10 surgical clips to } \\
\text { effectively mark the tumor bed }\end{array}$ \\
\hline $\begin{array}{l}\text { Furet et al. } \\
2014^{*}\end{array}$ & 18 & Surgical clips & No & $\begin{array}{l}\text { Use } 3 \text { or more clips to } \\
\text { effectively mark the tumor bed }\end{array}$ \\
\hline $\begin{array}{l}\text { Cross et al. } \\
2014^{*}\end{array}$ & 65 & Biozorb & No & $\begin{array}{l}\text { Device was effective in } \\
\text { marking the tumor bed }\end{array}$ \\
\hline $\begin{array}{l}\text { Cross et al. } \\
2017^{*}\end{array}$ & 108 & Biozorb & No & $\begin{array}{l}\text { Device was effective in } \\
\text { marking the tumor bed }\end{array}$ \\
\hline $\begin{array}{l}\text { Wiens et al. } \\
2018^{*}\end{array}$ & 143 & Biozorb & No & $\begin{array}{l}\text { Device was effective in } \\
\text { marking the tumor bed }\end{array}$ \\
\hline
\end{tabular}

$* 34,35,36,37,25$ (in order as shown in table)

\subsection{Incremental Cost-Utility Ratio (ICUR) and Dominance}

Given that surgical clips were substantially less expensive than Biozorb (\$50 versus \$1250), there would need to be a clinical benefit offered by Biozorb in order to justify the cost. Our literature review showed little clinical data noting any advantage favoring the Biozorb device over standard practice being the surgical clip placement. Both interventions appeared to mark the tumor cavity effectively per our findings listed in Table 1. Other clinical outcomes such as pain and infection were difficult to compare as there was little head to head comparison. From a cavity marking perspective, there were reports noted by Furet et al. and Pezner et al. noting tumor bed shifts with fewer clips (Pezner et al., 2013; Furet et al., 2014). This seemed to improve if there were more clips placed. Additionally, the concept of "migration" of surgical clips is less likely with surgical clips placed rather than radiological clip markers given the physical placement and capture of tissue when fixating the clip surgically in the operating room. While pain and discomfort have been noted with the Biozorb device, without having a comparison with clips, it is difficult to fault the device versus the surgery performed (and possible subsequent radiation). It was notable that Wiens et al. showed a statistically significant increase in the amount of radiation to the ipsilateral lung in the Biozorb arm compared to the traditional surgical clips arm but the long-term impact of this clinically is unknown (Wiens et al., 2018). Thus, clinical outcomes outside the cavity marking abilities of both interventions could not reliably occur given the scarce presence of peer reviewed, reasonable scientific data directly comparing each approach.

Table 2. Final Included Studies: Reported Post-Op Complications

\begin{tabular}{ll}
\hline Authors & Reported Complications \\
\hline Pezner et al. 2013* & Tumor bed shift with less than 4 clips \\
Furet et al. 2014* & Post-op intersection between clips and initial tumor site decreased with fewer clips \\
Cross et al. 2014* & None reported \\
Cross et al. 2017* & Pain/Discomfort: 1/108 (0.9\%) \\
& Erythema: 1/108 $(0.9 \%)$ \\
& Infection: 0/108 (0\%) \\
& Re-excision for positive margins: 13/108 (12.4\%) \\
Wiens et al. 2018* & Secondary Organ Radiation: \\
& Mean Gy heart (left sided), Biozorb vs. traditional clips $=2.24,2.18$ \\
& Mean Gy ipsilateral lung mean, Biozorb vs. traditional clips $=7.72,7.53$ \\
& V ipsilateral lung receiving 20Gy mean, Biozorb vs. traditional clips $=13.7,11.1$ \\
\hline
\end{tabular}

$* 34,35,36,37,25$ (in order as shown in table)

Given this, the clinical outcome comparing surgical clips to Biozorb based on their ability to mark the cavity should be noted to be equivalent. Therefore, with the cost difference advantage of $\$ 1200$ favoring surgical clips and an equivalent clinical outcome between both interventions, the ICUR quotient becomes infinity $(-\$ 1200 / 0)$ noting surgical clips to be a dominant choice over Biozorb.

\section{Discussion}

The results from our comprehensive literature search highlight the shortage of data comparing clinical benefit of 
both tumor bed marking techniques in the context of oncoplastic surgery. The lack of comparative literature makes it difficult to make a sound clinical judgment favoring the newer and more expensive Biozorb technique, and the need to show clinical benefit on Biozorb's behalf is essential if it is to be adopted as the newer tumor bed marking device over the standard (and much less expensive) surgical clips option. In sum, our results show that traditional surgical clips, in the absence of comparative data proving superior clinical benefit of Biozorb, is less costly and more cost-effective for healthcare resources for marking the breast tumor bed in the setting of oncoplastic surgery.

A cost-utility analysis is commonly used to determine the cost of particular interventions in terms of their utility, which includes quantity needed over a lifetime as well as quality of life. It has been used in a variety of surgical studies to date and have helped inform surgeon decisions (Chatterjee et al., 2015; Chatterjee et al., 2015; Chatterjee et al., 2014; Chatterjee et al., 2015; Fischer et al., 2016; Krishnan et al., 2016; Krishnan et al., 2015; Krishnan et al., 2014; Offodile et al., 2015; Thoma et al., 2012; Sheckter et al., 2018). Such a technique allows for identification of interventions with the best clinical outcomes and best value, which is especially important with the large healthcare costs associated with breast oncology management (Lang et al., 2014; Bekelman et al., 2014). The results of our study underscore the importance of assessing the value of a newer intervention before widespread adoption. When oncoplastic surgery is performed, the aesthetic advantages incurred by the local tissue rearrangement have long been documented and are well established without the use of Biozorb (Chatterjee et al., 2017; Silverstein et al., 2014; Clough et al., 2010; Anderson et al., 2005; Kelsall et al., 2017). However, Biozorb has been reported to have capabilities in marking the newly created tumor bed after an oncoplastic resection and reconstruction. Our PRISMA literature review has shown data that verifies Biozorb's ability in the marking of the cavity in certain oncoplastic operations but this is also equally true for the standard practice of surgical clip placement in oncoplastic surgery cases. Justifying the newer intervention of Biozorb at a higher price thus is not supported given the lack of any evidence showing Biozorb to be superior clinically to surgical clips.

There are a few limitations to consider to our study. First, the reliance on literature review and retrospective data make it difficult to understand possible confounding variables. The reliance of this study on other published studies could result in confirmation bias, as our analysis depended on unbiased clinical results of other studies. To overcome this, we performed a systematic review utilizing formalized guidelines to identify all potential studies. Second, the variability between surgical technique and outcomes could not be fully accounted for given the retrospective nature of the study. A future prospective study comparing Biozorb vs. traditional surgical clip placement is needed to address these limitations; nonetheless, the burden of proof in showing clinical superiority always lies on the newer intervention (Biozorb). Lastly, a cost-utility analysis is dependent on the reliability of available literature, which was difficult to account for. Per the results of our systematic review, only 5 articles to date have evaluated the use of either Biozorb or surgical clips in marking the tumor bed for radiation planning purposes.

Even with these limitations in place, there are important implications of this study on our healthcare's economy and clinical practice. In recent years, healthcare spending has garnered lots of attention from researchers, clinicians, policy-makers, and the public. A report in 2014 revealed that healthcare spending is nearly averaging about 17\% of the GDP (Lornezoni et al., 2014; Campbell, 2009). A healthy portion of healthcare spending goes towards oncological treatments and management. A study in 2009 estimated the life-time per patient costs of breast cancer to range anywhere from $\$ 20,000$ to $\$ 100,000$ ( $F u, 2012)$. Another study demonstrated the large up-front costs to the healthcare system (Gallet, 2017). Given these large costs and the high prevalence of breast cancer in the United States, it is imperative to understand ways to reduce cost without sacrificing clinical quality or health outcomes. From a health care cost perspective, adding potentially $\$ 1200$ per oncoplastic operation, which would occur with widespread Biozorb adoption, would add a non-justifiable cost to our already cost strained health system. Major breast cancer centers have reported performing oncoplastic surgery on approximately $18 \%$ of all their breast cancer patients (Carter et al., 2016). Assuming there are approximately 230,000 new breast cancers diagnosed a year with $18 \%$ of these cancers receiving oncoplastic surgery, widespread adoption of the Biozorb (assuming it will be used in every oncoplastic surgery case) would add approximately $\$ 50$ million dollars a year (over the use of surgical clips) to the health care system (Siegel et al., 2014). Again, no reasonable clinical data shows substantial clinical superiority of Biozorb over surgical clips to justify this annual high additional cost.

The importance in this article's results cannot be understated. Surgeons need to actively monitor value in the surgical decisions they make, by prioritizing clinical benefit while respecting potentially added cost whenever a newer technique or device is brought up as an alternative to an existing standard technique or device. This study's goal is not to show Biozorb as a clinically superior or inferior technique in marking a tumor bed when 
comparing it to surgical clips; it is to report, using PRISMA literature review guidelines, that limited data exists on this topic. However, the burden to prove Biozorb's clinical superiority lies with the company that manufactures the device, in ways such as appropriately funded comparative studies, etc. Most importantly, by using the results demonstrated here, the surgeon can be empowered to make an educated, value-based surgical decision, noting that no evidence present justifies value in the wide spread use of Biozorb over surgical clips in the marking of the tumor bed when performing oncoplastic surgery. Such ownership in value based surgical decision making by the surgeon maintains and justifies future autonomy and minimizes further regulation (by the hospital or government) on surgical choices.

\section{Conclusion}

In summary, literature and data on the clinical benefits of various tumor bed marking modalities in oncoplastic surgery is very limited. In oncoplastic surgery, the use of clips to mark the tumor bed is more cost-effective than the use of the Biozorb device which does not provide value given its relative high cost and lack of clinical advantage scientifically shown over the use of surgical clips. The burden of proof in value lies on the Biozorb device to show value before its widespread adoption in oncoplastic surgery since it is the newer and costlier intervention.

\section{Acknowledgements}

The project described was supported by the National Center for Advancing Translational Sciences, National Institutes of Health, Award Number TL1TR001062. The content is solely the responsibility of the authors and does not necessarily represent the official views of the NIH.

\section{References}

Alco, G., Igdem, S., Okkan, S., Dincer, M., Sarsenov, D., Ilgun, A. S., ... Ozmen, V. (2016). Replacement of the tumor bed following oncoplastic breast-conserving surgery with immediate latissimus dorsi mini-flap. Molecular and Clinical Oncology, 5(4), 365. https://doi.org/10.3892/mco.2016.984

Anderson, B. O., Masetti, R., \& Silverstein, M. J. (2005). Oncoplastic approaches to partial mastectomy: an overview of volume-displacement techniques. The Lancet Oncology, 6, 145-157. https://doi.org/10.1016/S1470-2045(05)01765-1

Asban, A., Homsy, C., Chen, L., Fisher, C., Losken, A., \& Chatterjee, A. (2018). A cost-utility analysis comparing large volume displacement oncoplastic surgery to mastectomy with single stage implant reconstruction in the treatment of breast cancer. The Breast, 41, 159-164. https://doi.org/10.1016/j.breast.2018.07.012

Bates, A. T., Swift, C. L., Kwa, W., Moravan, V., \& Aquino-Parsons, C. (2007): A Computed Tomography-based Protocol vs Conventional Clinical Mark-up for Breast Electron Boost. Clinical Oncology, 19, 349-355. https://doi.org/10.1016/j.clon.2007.02.002

Bedwinek, J. (1993). Breast conserving surgery and irradiation: The importance of demarcating the excision cavity with surgical clips. International Journal of Radiation Oncology, Biology, Physics, 26, 675-679. https://doi.org/10.1016/0360-3016(93)90287-6

Bekelman, J. E., Sylwestrzak, G., Barron, J., Liu, J., Epstein, A. J., Freedman, G., Malin, J., Emanuel, E. J. (2014). Uptake and costs of hypofractionated vs conventional whole breast irradiation after breast conserving surgery in the United States, 2008-2013. JAMA, 312, 2542. https://doi.org/10.1001/jama.2014.16616

Berry, M. G., Fitoussi, A. D., Curnier, A., Couturaud, B., \& Salmon, R. J. (2010). Oncoplastic breast surgery: A review and systematic approach. Journal of Plastic, Reconstructive \& Aesthetic Surgery, 63, 1233-1243. https://doi.org/10.1016/j.bjps.2009.05.006

Boersma, L. J., Janssen, T., Elkhuizen, P. H. M., Poortmans, P., van Der Sangen, M., Scholten, A. N., ... van Vliet, C. (2012). Reducing interobserver variation of boost-CTV delineation in breast conserving radiation therapy using a pre-operative CT and delineation guidelines. Radiotherapy and Oncology, 103, 178-182. https://doi.org/10.1016/j.radonc.2011.12.021

Braeuning, M. P., Burke, E. T., \& Pisano, E. D. (2000). Embolization coils as tumor markers for mammography in patients undergoing neoadjuvant chemotherapy for carcinoma of the breast. AJR American journal of roentgenology, 174, 251. https://doi.org/10.2214/ajr.174.1.1740251

Campbell, J. D., \& Ramsey, S. D. (2009). The Costs of Treating Breast Cancer in the US. A Synthesis of 
Published Evidence: Pharmacoeconomics, 27, 199-209.

Carter, S. A., Lyons, G. R., Kuerer, H. M., Bassett, R. L., Oates, S., Thompson, A., ... Hwang, R. F. (2016). Operative and Oncologic Outcomes in 9861 Patients with Operable Breast Cancer: Single-Institution Analysis of Breast Conservation with Oncoplastic Reconstruction. (Report). Annals of Surgical Oncology, 23, 3190. https://doi.org/10.1245/s10434-016-5407-9

Chatterjee, A. (2016). A Cost-Utility Analysis Comparing Oncoplastic Breast Surgery with Standard Lumpectomy in Large Breasted Women. Plastic and Reconstructive Surgery - Global Open, 4(4S Suppl), 35-35. https://doi.org/10.1097/GOX.0000000000000694

Chatterjee, A., Dayicioglu, D., Khakpour, N., \& Czerniecki, B. J. (2017).Oncoplastic Surgery: Keeping It Simple With 5 Essential Volume Displacement Techniques for Breast Conservation in a Patient With Moderate- to Large-Sized Breasts. Cancer Control., 24(4), 1073274817729043. https://doi.org/10.1177/1073274817729043.

Chatterjee, A., Krishnan, N. M., Van Vliet, M. M., Powell, S. G., Rosen, J. M., \& Ridgway, E. B. (2013). A comparison of free autologous breast reconstruction with and without the use of laser-assisted indocyanine green angiography: a cost-effectiveness analysis. Plastic and reconstructive surgery, 131, 693e. https://doi.org/10.1097/PRS.0b013e31828659f4

Chatterjee, B. A., Ramkumar, B. D., Dawli, F. T., Nigriny, A. J., Stotland, B. M., \& Ridgway, B. E. (2015). The Use of Mesh versus Primary Fascial Closure of the Abdominal Donor Site When Using a Transverse Rectus Abdominis Myocutaneous Flap for Breast Reconstruction: A Cost-Utility Analysis. Plastic and Reconstructive Surgery, 135, 682-689. https://doi.org/10.1097/PRS.0000000000000957

Chatterjee, J. A., Macarios, C. D., Griffin, C. L., Kosowski, C. T., Pyfer, C. B., Offodile, C. A., ... Attwood, C. J. (2015). Cost-Utility Analysis: Sartorius Flap versus Negative Pressure Therapy for Infected Vascular Groin Graft Managment. Plastic and Reconstructive Surgery, 3, e566-e566. https://doi.org/10.1097/GOX.0000000000000551

Chatterjee, M. A., Krishnan, M. N., \& Rosen, M. J. (2014). Complex Ventral Hernia Repair Using Components Separation with or without Synthetic Mesh: A Cost-Utility Analysis. Plastic and Reconstructive Surgery, 133, 137-146. https://doi.org/10.1097/01.prs.0000436835.96194.79

Chatterjee, S. A., Kosowski, C. T., Pyfer, C. B., Fisher, C. C., Tchou, C. J., \& Maddali, C. S. (2015). A Cost-Utility Analysis Comparing the Sartorius versus the Rectus Femoris Flap in the Treatment of the Infected Vascular Groin Graft Wound. Plastic and Reconstructive Surgery, 135, 1707-1714. https://doi.org/10.1097/PRS.0000000000001267

Clough, K., Kaufman, G., Nos, C., Buccimazza, I., \& Sarfati, I. (2010). Improving Breast Cancer Surgery: A Classification and Quadrant per Quadrant Atlas for Oncoplastic Surgery. Annals of Surgical Oncology, 17, 1375-1391. https://doi.org/10.1245/s10434-009-0792-y

Cross, M., Lebovic, G., Ross, J., Jones, S., Smith, A., \& Harms, S. (2017). Impact of a Novel Bioabsorbable Implant on Radiation Treatment Planning for Breast Cancer. Official Journal of the International Society of Surgery/Société Internationale de Chirurgie, 41, 464-471. https://doi.org/10.1007/s00268-016-3711-y

Cross, M., Lebovic, G., Stubbs, J., Ross, J., Jones, S., \& Beck, T. (2014). Identifying the surgical cavity following oncoplastic breast surgery. J Clin Oncol., 32. https://doi.org/10.1200/jco.2014.32.26

Den Hartogh, M D., Philippens, M. E. P., Van Dam, I. E., Kleynen, C. E., Tersteeg, R. J. H. A., Pijnappel, R. M., ... Van Den Bongard, H. D. (2014). MRI and CT imaging for preoperative target volume delineation in breast-conserving therapy. Radiat Oncol., 26(9), 63. https://doi.org/10.1186/1748-717X-9-63

Denham, J. W., Sillar, R. W., \& Clarke, D. (1991). Boost dosage to the excision site following conservative surgery for breast cancer: It's easy to miss! Clinical Oncology, 3, 257-261. https://doi.org/10.1016/S0936-6555(05)80873-8

Drummond, M. (2005). Methods for the economic evaluation of health care programmes, ed 3rd ed. Oxford; New York, Oxford ; New York : Oxford University Press.

Dukhovny, D. (2011). Economic evaluation with clinical trials in neonatology. NeoReviews; in JA Z (ed). NeoReviews, 12, 69-75.

Eaton, B. R., Losken, A., Okwan-Duodu, D., Schuster, D. M., Switchenko, J. M., Mister, D., Godette, K., \& Torres, M. A. (2014). Local Recurrence Patterns in Breast Cancer Patients Treated with Oncoplastic 
Reduction Mammaplasty and Radiotherapy.(Report). Annals of Surgical Oncology, 21, 93. https://doi.org/10.1245/s10434-013-3235-8

Fischer, P. J., Basta, N. M., Krishnan, M. N., Wink, D. J., \& Kovach, J. S. (2016). A Cost-Utility Assessment of Mesh Selection in Clean-Contaminated Ventral Hernia Repair. Plastic and Reconstructive Surgery, 137, 647-659. https://doi.org/10.1097/01.prs.0000475775.44891.56

Fu, A. Z., \& Jhaveri, M. (2012). Healthcare cost attributable to recently-diagnosed breast cancer in a privately-insured population in the United States. Journal of Medical Economics, 15, 688-694. https://doi.org/10.3111/13696998.2012.673524

Furet, E., Peurien, D., Fournier-Bidoz, N., Servois, V., Reyal, F., Fourquet, A., Rouzier, R., \& Kirova, Y. M. (2014). Plastic surgery for breast conservation therapy: How to define the volume of the tumor bed for the boost?. European Journal of Surgical Oncology, 40. https://doi.org/10.1016/j.ejso.2014.03.009

Gallet, C. A., \& Doucouliagos, H. (2017). The impact of healthcare spending on health outcomes: A meta-regression analysis. Social Science \& Medicine, 179, 9-17. https://doi.org/10.1016/j.socscimed.2017.02.024

Grosse, S. D. (2008). Assessing cost-effectiveness in healthcare: history of the $\$ 50,000$ per QALY threshold. Expert Review of Pharmacoeconomics \& Outcomes Research, 8, 165-178. https://doi.org/10.1586/14737167.8.2.165

Harrington, K. J., Harrison, M., Bayle, P., Evans, K., Dunn, P. A., Lambert, H. E., Saidan, Z., Lynn, J., \& Stewart, J. S. W. (1996). Surgical clips in planning the electron boost in breast cancer: A qualitative and quantitative evaluation. International Journal of Radiation Oncology, Biology, Physics, 34, 579-584. https://doi.org/10.1016/0360-3016(95)02090-X

Hartogh, M., Asselen, B., Monninkhof, E., Bosch, M., Vulpen, M., Diest, P., Gilhuijs, K., ... Bongard, H. (2011). Excised and irradiated volumes in relation to the tumor size in breast-conserving therapy. Breast Cancer Research and Treatment, 129, 857-865. https://doi.org/10.1007/s10549-011-1696-7

Kelsall, J. E., McCulley, S. J., Brock, L., Akerlund, M. T. E., \& Macmillan, R. D. (2017). Comparing oncoplastic breast conserving surgery with mastectomy and immediate breast reconstruction: Case-matched patient reported outcomes. Journal of Plastic, Reconstructive \& Aesthetic Surgery, 70, 1377-1385. https://doi.org/10.1016/j.bjps.2017.05.009

Kirova, Y. M., Servois, V., Reyal, F., Peurien, D., Fourquet, A., \& Fournier-Bidoz. (2011). Use of deformable image fusion to allow better definition of tumor bed boost volume after oncoplastic breast surgery. Surgical Oncology, 20, e123-e125. https://doi.org/10.1016/j.suronc.2011.02.001

Krishnan, M. N., Fischer, P. J., Basta, N. M., \& Nahabedian, Y. M. (2016). Is Single-Stage Prosthetic Reconstruction Cost Effective? A Cost-Utility Analysis for the Use of Direct-to-Implant Breast Reconstruction Relative to Expander-Implant Reconstruction in Postmastectomy Patients. Plastic and Reconstructive Surgery, 138, 537-547. https://doi.org/10.1097/PRS.0000000000002428

Krishnan, M. N., Purnell, Y. C., Nahabedian, L. M., Freed, F. G., Nigriny, M. J., Rosen, D. J., \& Rosson, D. G. (2015). The Cost Effectiveness of the DIEP Flap Relative to the Muscle-Sparing TRAM Flap in Postmastectomy Breast Reconstruction. Plastic and Reconstructive Surgery, 135, 948-958. https://doi.org/10.1097/PRS.0000000000001125

Krishnan, N. M., Chatterjee, A., Rosenkranz, K. M., Powell, S. G., Nigriny, J. F., \& Vidal, D. C. (2013). The cost effectiveness of acellular dermal matrix in expander-implant immediate breast reconstruction. Journal of Plastic, Reconstructive \& Aesthetic Surgery 2014, 67, 468-476. https://doi.org/10.1016/j.bjps.2013.12.035

Landis, D. M. (2007). Variability Among Breast Radiation Oncologists in Delineation of the Postsurgical Lumpectomy Cavity. International Journal of Radiation Oncology, Biology and Physics, 67. https://doi.org/10.1016/j.ijrobp.2006.11.026

Lang, K., Huang, H., Sasane, M., Paly, V., Hao, Y., \& Menzin, J. (2014). Survival, healthcare resource use and costs among stage IV ER plus breast cancer patients not receiving HER2 targeted therapy: a retrospective analysis of linked SEER-Medicare data. BMC Health Serv Res., 14. https://doi.org/10.1186/1472-6963-14-298

Lorenzoni, L., Belloni, A., \& Sassi, F. (2014). Health-care expenditure and health policy in the USA versus other high-spending OECD countries. The Lancet, 384, 83-92. https://doi.org/10.1016/S0140-6736(14)60571-7 
Masetti, R., Di Leone, A., Franceschini, G., Magno, S., Terribile, D., Fabbri, M. C., \& Chiesa, F. (2006). Oncoplastic Techniques in the Conservative Surgical Treatment of Breast Cancer: An Overview. Breast Journal, 12, S174-S180. https://doi.org/10.1111/j.1075-122X.2006.00331.x

Messer, P. M., Kirikuta, I. C., Bratengeier, K., \& Flentje, M. (1997). CT planning of boost irradiation in radiotherapy of breast cancer after conservative surgery. Radiotherapy and Oncology, 42, 239-243. https://doi.org/10.1016/S0167-8140(96)01891-9

Metcalfe, P., Liney, G. P., Holloway, L., Walker, A., Barton, M., Delaney, G. P., Vinod, S., \& Tomé, W. (2013). The Potential for an Enhanced Role for MRI in Radiation-Therapy Treatment Planning. Technology in Cancer Research \& Treatment, 12, 429-446. https://doi.org/10.7785/tcrt.2012.500342

Neumann, P. J., Cohen, J. T., \& Weinstein, M. C. (2014). Updating Cost-Effectiveness - The Curious Resilience of the \$50,000-per-QALY Threshold. The New England Journal of Medicine, 371, 796-797. https://doi.org/10.1056/NEJMp1405158

Offodile, C. A., Chatterjee, S. A., Vallejo, C. S., Fisher, C. C., Tchou, C. J., \& Guo, C. L. (2015). A Cost-Utility Analysis of the Use of Preoperative Computed Tomographic Angiography in Abdomen-Based Perforator Flap Breast Reconstruction. Plastic and Reconstructive Surgery, 135, 662e-669e. https://doi.org/10.1097/PRS.0000000000001133

Oh, K. S., Kong, F. M., Griffith, K. A., Yanke, B., \& Pierce, L. J. (2006). Planning the breast tumor bed boost: Changes in the excision cavity volume and surgical scar location after breast-conserving surgery and whole-breast irradiation. International Journal of Radiation Oncology, Biology and Physics, 66. https://doi.org/10.1016/j.ijrobp.2006.04.042

Penninkhof, J., Quint, S., Boer, H. D., Mens, J. W., Heijmen, B., \& Dirkx, M. (2009). Surgical clips for position verification and correction of non-rigid breast tissue in simultaneously integrated boost (SIB) treatments. Radiotherapy and Oncology, 90, 110-115. https://doi.org/10.1016/j.radonc.2008.10.009

Petersen, R. P. (2007). Target Volume Delineation for Partial Breast Radiotherapy Planning: Clinical Characteristics Associated with Low Interobserver Concordance. International Journal of Radiation Oncology, Biology and Physics, 69. https://doi.org/10.1016/j.ijrobp.2007.01.070

Pezner, D. R., Tan, C. M., Clancy, L. S., Chen, L. Y-J., Joseph, L. T., \& Vora, L. N. (2013).Radiation Therapy for Breast Cancer Patients Who Undergo Oncoplastic Surgery: Localization of the Tumor Bed for the Local Boost. American Journal of Clinical Oncology, 36, 535-539. https://doi.org/10.1097/COC.0b013e318256efba

Piper, M., Peled, A. W., \& Sbitany, H. (2015). Oncoplastic breast surgery: current strategies. Gland surgery, 4, 154. https://doi.org/10.3978/j.issn.2227-684X.2015.03.01

Sheckter, C. C., Matros, E., \& Momeni, A. (2018). Assessing value in breast reconstruction: A systematic review of cost-effectiveness studies. Journal of Plastic, Reconstructive \& Aesthetic Surgery, 71, 353-365.

Siegel, R., Ma, J., Zou, Z., \& Jemal, A. (2014). Cancer statistics, 2014. CA: A Cancer Journal for Clinicians, 64, 9-29. https://doi.org/10.3322/caac.21208

Silverstein, M. J., Mai, T., Savalia, N., Vaince, F., \& Guerra, L. (2014). Oncoplastic breast conservation surgery: The new paradigm. J Surg Oncol., 110, 82-89. https://doi.org/10.1002/jso.23641

Thoma, A., Ignacy, T. A., Ziolkowski, N., \& Voineskos, S. (2012). The performance and publication of cost-utility analyses in plastic surgery: Making our specialty relevant. Can J Plast Surg., 20, 187-193. https://doi.org/10.1016/j.bjps.2017.09.010

Ubel, P. A., Hirth, R. A., Chernew, M. E., \& Fendrick, A. M. (2003). What Is the Price of Life and Why Doesn't It Increase at the Rate of Inflation?. Archives of Internal Medicine, 163, 1637-1641. https://doi.org/10.1001/archinte.163.14.1637

Ward, R. C., Wiggins, D. L., Donegan, L., Collins, S., Lourenco, A. P., \& Mainiero, M. B. (2018). BioZorb tissue marker as seen on multiple imaging modalities. Breast Journal, 24, 207-209. https://doi.org/10.1111/tbj.12870

Weed, D. W., Yan, D., Martinez, A. A., Vicini, F. A., Wilkinson, T. J., \& Wong, J. (2004). The validity of surgical clips as a radiographic surrogate for the lumpectomy cavity in image-guided accelerated partial breast irradiation. International Journal of Radiation Oncology, Biology, Physics, 60, 484-492.

https://doi.org/10.1016/j.ijrobp.2004.03.012 
Wiens, N., Torp, L., Wolff, B., Wert, Y., Barton, K., Weksberg, D., \& Wilson-Dagar, J. (2018).Effect of BioZorb $₫$ surgical marker placement on post-operative radiation boost target volume. Journal of Radiation Oncology, 7, 175-179. https://doi.org/10.1007/s13566-017-0339-y

Wilson, S. H. (1987). Methods for the economic evaluation of health care programmes. Journal of Epidemiology and Community Health, 41, 355.

Youn, I., Choi, S., Kook, S., Choi, Y., Park, C., Park, Y., \& Kim, D. (2015). Ultrasonography-Guided Surgical Clip Placement for Tumor Localization in Patients Undergoing Neoadjuvant Chemotherapy for Breast Cancer. J Breast Canc., 18, 44-49. https://doi.org/10.4048/jbc.2015.18.1.44

\section{Copyrights}

Copyright for this article is retained by the author(s), with first publication rights granted to the journal.

This is an open-access article distributed under the terms and conditions of the Creative Commons Attribution license (http://creativecommons.org/licenses/by/4.0/). 